\title{
Comparison and Analysis of Calculation Methods for Acid Dew Point of Coal-Fired Boiler Flue Gas Based on $\mathrm{So}_{3}$ Concentration
}

\author{
Meng ZHANG ${ }^{\mathrm{a}, 1}$, Ziwen ZHANG ${ }^{\mathrm{b}}$, Lin $\mathrm{Ma}^{\mathrm{a}}$, Junjie ZHAO ${ }^{\mathrm{b}}$, Jin $\mathrm{YANG}^{\mathrm{b}}$, Shendong \\ $\mathrm{Li}^{\mathrm{b}}$, Hongtao $\mathrm{Yu}^{\mathrm{b}}$ and Qi Wang ${ }^{\mathrm{b}}$ \\ ${ }^{a}$ China Datang Group Research Institute of Science and Technology Co., Ltd. Thermal \\ Power Technology Research Institute, Beijing, China \\ b Zhejiang Datang Wushashan Power Generation Co., Ltd, NingBo, China
}

\begin{abstract}
In order to accurately predict the acid dew point of coal-fired power plant boiler flue gas and seek a more suitable formula for calculating the acid dew point of flue gas in actual production, the least square method is used to compare the common acid dew point calculation formulas based on relevant test data. And obtain the acid dew point calculation formula based on sulfur trioxide. The fitting formulas of Taylor and Xiang Boxiang's data tables were obtained by fitting and compared with common calculation formulas. The results show that the calculation form of Verhoff\&Branchero calculation formula is more suitable for the simulation of acid dew point calculation formula based on sulfur trioxide. Together, Taylor's calculation formula has a wider range of values and is more suitable for field applications, But when the sulfur trioxide concentration is lower than $20 \mathrm{ppm}$, the Haase calculation formula has higher calculation accuracy.
\end{abstract}

Keywords. Sulfur trioxide, acid dewpoint, least squares, coal fired boiler.

\section{Introduction}

In recent years, the pollutant emission standards of coal-fired power plants have been continuously improved[1], and the cost of pollutant control has increased significantly. How to effectively achieve energy conservation and emission reduction has become the focus of coal-fired power plants. The exhaust gas heat utilization at the tail of coal-fired boiler can further reduce the exhaust gas temperature, improve the boiler efficiency[2,3] and reduce the coal consumption of power generation [4,5]. Low exhaust temperature can improve the capture ability of the dust collector, thereby improving the dust removal efficiency and reducing the dust content in the exhaust. At the same time, reducing the exhaust temperature can improve the efficiency of wet desulfurization system[6,7], and also reduce the evaporation of desulfurization slurry and the humidity of flue gas at the outlet of desulfurization tower. Low flue gas humidity is of great

${ }^{1}$ Corresponding Author, Meng ZHANG, China Datang Group Research Institute of Science and Technology Co., Ltd. Thermal Power Technology Research Institute, Beijing, China; E-mail: zhangmeng@cdt-kxjs.com. 
significance to reduce the plume phenomenon of power station. However, relevant research [8] shows that although thermal recovery can achieve the purpose of energy saving and emission reduction, it also brings the risk of low temperature corrosion of the heating surface. Acid dew point of flue gas is the main factor restricting low temperature corrosion $[9,10]$.It can be seen that although the recovery of flue gas heat from the tail of coal-fired boiler is an important means to effectively improve boiler efficiency, reduce pollutant emissions[11] and achieve energy saving and emission reduction, this technology is restricted by the acid dew point of flue gas[12] . Therefore, accurate prediction of acid dew point in flue gas is of great significance to avoid low temperature corrosion and promote the development of heat recovery technology.

In order to seek the calculation formula of acid dew point with higher accuracy, scholars have done a lot of research. ZareNezhad et al.[13,14] proposed a numerical prediction model of flue gas acid dew point based on neural network according to the relevant data of the oil industry. Xiang et al[15]. proposed a semi-empirical model for numerical prediction of flue gas acid dew point based on experimental measurement data and theoretical derivation. Bahadori et al. [16] proposed an acid dew point calculation method based on Vandermon determinant considering fuel type, sulfur content and excess air coefficient. Relevant scholars [17,18] conducted numerical analysis on acid dew point of flue gas based on gas-liquid equilibrium effect and multi-component diffusion effect. Xian et al [19]modified the BapaHoB formula according to the experimental data. Song et al[20]studied the effect of the content of calcium oxide and magnesium oxide in fly ash on the acid dew point value by means of experiments. Jia et al[21] fitted Muller curve and Halstead curve by fitting software. Wang et al[22]discussed the effect of oxygen-enriched combustion on acid dew point by theoretical calculation. Xie et al[23] modified the Лероеян calculation formula according to the actual sulfur dioxide concentration in flue gas at the inlet of the desulfurization tower. Zhang et al[24] pointed out the deficiency of Гаврцлов formula and corrected it through analysis.Xiang[25] obtained a new acid dew point calculation formula based on the theoretical calculation results of Aspen software. Li Jun et al[26]modified the formula based on field measurement data and theoretical analysis.Xiang et al. [27] obtained a method for calculating acid dew point based on flue gas composition by fitting field measurement data. However, the above calculation methods have not been effectively verified, and relevant scholars found through field measurement that the prediction results of common acid dew point calculation formulas were significantly higher than their actual values, which to some extent lost guiding significance for the design and operation of heat recovery device. This is mainly because the commonly used acid dew point calculation formula obtains theoretical values based on sulfur trioxide concentration or converted sulfur content in coal combustion. However, the concentration of sulfur trioxide in flue gas and the content of combustible sulfur in coal cannot be accurately calculated or measured, so the accuracy of commonly used calculation formulas is generally low. However, sulfur dioxide is detected in real time as an important index to measure the sulfur content of flue gas, but the existing technology can accurately measure the index content. Therefore, a calculation formula of flue gas acid dew point of coal-fired boiler based on sulfur dioxide concentration measurement value can reduce the calculation error of flue gas acid dew point caused by inaccurate measurement or calculation to a certain extent.

According to the calculation formula of flue gas acid dew point which is quoted frequently at home and abroad, this paper summarizes the calculation forms of acid dew 
point calculation formula to obtain three calculation formulas of acid dew point. Based on the calculation formula of common flue gas acid dew point, the A.Taylor acid dew point calculation table [24] and the experimental data of Tsinghua University Xiang Boxiang [21] were fitted by the least square method. Through the comparative analysis of the mean square error of the fitting results and the coefficient of determination, the best formula form and fitting formula are determined. Finally, the latest fitting formula is compared and analyzed with the flue gas acid dew point calculation formula which is quoted frequently at home and abroad.

\section{Mathematical Model}

The so-called least square method is to obtain discrete data points $\left(\mathrm{x}_{\mathrm{i}}, \mathrm{y}_{\mathrm{i}}\right)(\mathrm{i}=1, \ldots, \mathrm{m})$ according to the experiment, and the determined curve form $\mathrm{y}=\mathrm{P}\left(\mathrm{x}, \mathrm{a}_{0}, \mathrm{a}_{1}, \mathrm{a}_{2}, \ldots, \mathrm{a}_{\mathrm{n}}\right)$, calculate the error sum of squares at a given point (as in formula 1), and default the coefficient matrix corresponding to the minimum error sum of squares to the positive determination coefficient matrix in the fitting formula, so as to convert the curve fitting problem into a multivariate function for the extreme Value problem.

$$
\mathrm{F}\left(a_{0}, a_{1}, \ldots, a_{n}\right)=\sum_{\mathrm{i}=1}^{\mathrm{m}} \omega_{\mathrm{i}}\left[\mathrm{P}\left(x_{\mathrm{i}}, a_{0}, a_{1} \ldots, a_{n}\right)-y_{i}\right]^{2} \quad(n<m+1)
$$

Where, $\omega_{\mathrm{i}}-$ Full coefficient of point $\left(\mathrm{x}_{\mathrm{i}}, \mathrm{y}_{\mathrm{i}}\right), \omega_{\mathrm{i}}>0(\mathrm{i}=1, \ldots, \mathrm{m})$.

In other words, the least squares method is to solve the multivariate function optimization problem, that is, by solving the parameter ai $(i=0,1, \cdots, n)$, the minimum value of $a_{i}(i=0,1, \cdots, n)$ is obtained, that is, the parameter that satisfies the equation 2 is solved $\mathrm{ai}^{*}=\mathrm{a}_{\mathrm{i}}$.

$$
\mathrm{F}\left(a_{0}^{*}, a_{1}^{*}, \ldots, a_{n}^{*}\right) \leq \mathrm{F}\left(a_{0}, a_{1}, \ldots, a_{n}\right)
$$

Basic knowledge of mathematics shows that the necessary condition for the extreme value of a function is Equation 3, but Equation 3 is not a necessary condition for the extreme value of a function.In particular, when $F$ is a nonlinear function of $a_{i}$, it is called a nonlinear least squares problem, and when $F$ is a linear function of $a_{i}$, it is called a linear least squares problem.

$$
\frac{\partial F}{\partial a_{k}}=0 \quad(\mathrm{k}=0,1, \ldots, \mathrm{n})
$$

The relevant theory of the least square method can also be extended to the fitting of multivariate functions. Suppose a certain multivariate function is known:

$$
y=f\left(x_{1}, x_{2}, \ldots, x_{l}\right)
$$


When the observation array of the multivariate function $\left(\mathrm{x}_{1}, \mathrm{x}_{2}, \cdots, \mathrm{x}_{\mathrm{i}}, \mathrm{y}_{\mathrm{i}}\right)$ $(i=1, \cdots, m)$ is obtained, and the observation array is required to satisfy the following relationship:

$$
p\left(\mathrm{x}_{1}, x_{2}, \ldots, x_{l}\right)=\sum_{\mathrm{k}=1}^{\mathrm{m}} a_{k} \varphi_{k}\left(\mathrm{x}_{1}, x_{2}, \ldots, x_{l}\right) \quad(\mathrm{n}<\mathrm{m}+1)
$$

When the value of Equation 6 is minimized, the least squares problem of the Australian dollar function of the degree is solved.

$$
F\left(a_{0}, a_{1}, \ldots, a_{n}\right)=\sum_{\mathrm{i}=1}^{\mathrm{m}} w_{\mathrm{i}}\left[p\left(x_{1 i}, x_{2 i}, \ldots, x_{l i}\right)-y_{i}\right]^{2}
$$

\section{The Fitting Form of Common Acid Dew Point Calculation Formula and Data Fitting}

Relevant scholars at home and abroad have conducted a lot of research on acid dew point prediction methods, and put forward a variety of acid dew point calculation formulas based on different models. The calculation formulas can be roughly divided into two categories[18,29]: one is the calculation formula obtained by fitting a large number of field measurement data, such as the calculation formula of P.A.Лероеян; the other is derived from thermodynamic theory and experimental data The calculated formula [15], such as the AGOkkes formula. There are dozens of calculation formulas for acid dew point at home and abroad, and the calculation formulas with higher frequency cited in domestic literature are summarized in Table 1.

\begin{tabular}{|c|c|c|}
\hline name & Form of calculation & numbering \\
\hline $\begin{array}{l}\text { Verhoff\&Bran } \\
\text { chero } \\
{[2]}\end{array}$ & $\frac{1000}{t_{\mathrm{adp}}+273.15}=2.9982-0.1376 \lg p_{\mathrm{H}_{2} \mathrm{O}}-0.2674 \lg p_{\mathrm{SO}_{3}}+0.03287 \lg p_{\mathrm{H}_{2} \mathrm{O}} \lg p_{\mathrm{SO}_{3}}$ & (1) \\
\hline A.G.Okkes[12] & $t_{\text {adp }}=10.8809+27.6 \log p_{\mathrm{H}_{2} \mathrm{O}}+10.83 \log p_{\mathrm{SO}_{3}}+1.06\left(\log p_{\mathrm{SO}_{3}}+2.9943\right)^{2.19}$ & (2) \\
\hline $\begin{array}{l}\text { Semi-empirical } \\
\text { formula }\end{array}$ & $t_{a d p}=t_{w d p}+B\left(P_{\mathrm{H}_{2} \mathrm{SO}_{4}}\right)^{n}$ & (3) \\
\hline Halstead[13] & $t_{\text {adp }}=113.0219+15.0777 \lg r_{\mathrm{H}_{2} \mathrm{SO}_{4}}+2.0975\left(\lg r_{\mathrm{H}_{2} \mathrm{SO}_{4}}\right)^{2}$ & (4) \\
\hline $\begin{array}{c}\text { Haase\&Borgm } \\
\text { ann } \\
{[14-15]}\end{array}$ & $t_{\text {adp }}=255+18.7 \log p_{\mathrm{H}_{2} \mathrm{Oa}}+27.6 \log p_{\mathrm{SO}_{3} \mathrm{a}}$ & (5) \\
\hline $\begin{array}{l}\text { И.А.ВараНоВ } \\
{[14-15]}\end{array}$ & $t_{\text {adp }}=186+20 \log r_{\mathrm{H}_{2} \mathrm{O}_{h}}+26 \log r_{S_{3} h}$ & (6) \\
\hline $\begin{array}{l}\text { Müller } \\
{[16-17]}\end{array}$ & $t_{\mathrm{adp}}=116.5515+16.06329 \log r_{\mathrm{SO}_{3}}+1.05377\left(\log r_{\mathrm{SO}_{3}}\right)^{2}$ & (7) \\
\hline
\end{tabular}

Table 1. Summary of common acid dew point calculation formulas 
Ohtsuka

[16-17,20]

Р.А.Лероеян

[18]

$$
t_{\mathrm{adp}}=20 \log r_{\mathrm{SO}_{3}}+a-80
$$

1) $\mathrm{a}$ is a constant related to the volume fraction of water vapor in the flue gas. When the volume fraction of water vapor is $5 \%, \mathrm{a}=184$; when the volume fraction of water vapor is $10 \%$, $\mathrm{a}=194$; when the volume fraction of water vapor is $15 \%, \mathrm{a}=201 . \beta$ is a constant related to the excess air coefficient at the outlet of the furnace, and it is taken as 125 in general engineering calculations. $\alpha$ fh is the fly ash content, and the pulverized coal furnace takes 0.8 to 0.9 .

2) $\mathrm{pH} 2 \mathrm{O}$ is the partial pressure of water vapor in the flue gas, $\mathrm{Pa}$; pSO3 is the partial pressure of $\mathrm{SO} 3$ in the flue gas, $\mathrm{Pa} ; \mathrm{pH} 2 \mathrm{Oa}$ is the partial pressure of water vapor in the flue gas, $0.1 \mathrm{Mpa}$; $\mathrm{pSO} 3 \mathrm{a}$ is the partial pressure of SO3 in the flue gas, $0.1 \mathrm{Mpa}$.

3) $\mathrm{rH} 2 \mathrm{SO} 4$ is the volume fraction of sulfuric acid vapor in the flue gas, $\mathrm{mL} / \mathrm{m} 3 ; \mathrm{rSO} 3$ is the volume fraction of $\mathrm{SO} 3$ in the flue gas, $\mathrm{mL} / \mathrm{m} 3 ; \mathrm{rH} 2 \mathrm{O}$ is the volume fraction of water vapor in the flue gas, $\%$; $\mathrm{rH} 2 \mathrm{Oa}$ is the partial pressure of water vapor in the flue gas, atm; rSO3h is the volume fraction of SO3 in the flue gas, $\%$.

4) Szs is the converted sulfur content, $\mathrm{Szs}=4187 \mathrm{Sar} / \mathrm{Qnet}$, where Sar is the received base sulfur content, and Qnet is the received base low calorific value. Azs is converted ash, Azs=4 187Sar /Qnet, where Aar is received base ash.

5) B, n-calculation index, see Table 2

Table 2. Summary of common acid dew point calculation formulas

\begin{tabular}{ccccccccccc}
\hline PH2O+PH2SO4 & $\mathrm{Pa}$ & 2000 & 4000 & 6000 & 8000 & 12000 & 16000 & 20000 & 28000 & 36000 \\
\hline \multirow{2}{*}{$\mathrm{A}$} & $\mathrm{B}$ & 200.2 & 202.4 & 204.2 & 206.3 & 210.2 & 214.2 & 218.3 & 226.4 & 234.0 \\
& $\mathrm{n}$ & 0.1224 & 0.0907 & 0.0732 & 0.0659 & 0.062 & 0.0636 & 0.0661 & 0.0720 & 0.0780 \\
& $\mathrm{~B}$ & 289.9 & 289.3 & 288.7 & 288.7 & 286.9 & 285.6 & 284.4 & 281.9 & - \\
$\mathrm{B}$ & $\mathrm{B}$ & 0.0987 & 0.1014 & 0.1038 & 0.1063 & 0.1107 & 0.1145 & 0.1178 & 0.1229 & - \\
\hline
\end{tabular}

In the formulas for calculating the acid dew point using flue gas components, the calculation form of the Verhoff \& Branchero calculation formula is the calculation form used by most acid vapors ( $\mathrm{HNO} 3, \mathrm{HCl}$, etc.), and there are two more forms in each formula. The three calculation forms are summarized in Table 3.

In order to analyze the rationality of each calculation form, this paper adopts the common A.Taylor acid dew point calculation table in domestic literature [24], and the experimental data of Tsinghua University Xiang Boxiang [21] for fitting analysis, of which Taylor data is shown in Table 4. Xiang Boxiang's experimental data are shown in Table 5.

Table 3. Common acid dew point calculation forms

\begin{tabular}{|c|c|}
\hline Form 1 & $\frac{\mathrm{A}}{t_{\mathrm{adp}}+273.15}=\mathrm{B}-\mathrm{C} \log p_{\mathrm{H}_{2} \mathrm{O}}-\mathrm{D} \log p_{\mathrm{SO}_{3}}+\mathrm{E} \log p_{\mathrm{H}_{2} \mathrm{O}} \log p_{\mathrm{SO}_{3}}$ \\
\hline Form 2 & $t_{\mathrm{adp}}=\mathrm{A}+\mathrm{B} \log p_{\mathrm{H}_{2} \mathrm{O}}+\mathrm{C} \log p_{\mathrm{SO}_{3}}+\mathrm{D}\left(\log p_{\mathrm{SO}_{3}}+\mathrm{E}\right)^{\mathrm{F}}$ \\
\hline Form 3 & $t_{\text {adp }}=\mathrm{A}+\mathrm{B} \log p_{\mathrm{H}_{2} \mathrm{SO}_{4}}+\mathrm{C} \log p_{\mathrm{H}_{2} \mathrm{O}}$ \\
\hline
\end{tabular}


Table 4. Taylor acid dew point calculation data table

\begin{tabular}{|c|c|c|c|c|}
\hline \multirow{2}{*}{$\begin{array}{l}\text { Sulfuric acid } \\
\text { vapor } \\
\text { content } \\
\%\end{array}$} & \multicolumn{3}{|c|}{$\begin{array}{l}\text { Water vapor partial pressure and corresponding water } \\
\text { dew point value } \\
{ }^{\circ} \mathrm{C}\end{array}$} & \multirow{2}{*}{$\begin{array}{l}\text { According to the data table of } \\
\text { A.taylor at the same acid dew } \\
\text { point, the amount of sulfuric acid } \\
\text { vapor } \\
\%\end{array}$} \\
\hline & 5000 & 8300 & 24500 & \\
\hline 0 & 33 & 43 & 64 & 0 \\
\hline \multirow[t]{2}{*}{10} & 40 & 48 & 70 & $0.0001 \%$ \\
\hline & 46 & 53 & 74 & $0.0002 \%$ \\
\hline \multirow[t]{2}{*}{50} & 63 & 68 & 87 & $0.0005 \%$ \\
\hline & 73 & 78 & 96 & $0.0007 \%$ \\
\hline \multirow[t]{2}{*}{100} & 86 & 91 & 105 & $0.001 \%$ \\
\hline & 101 & 107 & 119 & $0.0015 \%$ \\
\hline \multirow[t]{2}{*}{200} & 116 & 121 & 130 & $0.002 \%$ \\
\hline & 127 & 131 & 139 & $0.0025 \%$ \\
\hline
\end{tabular}

Table 5. Summary table of Xiangboxiang acid dew point experiment data

\begin{tabular}{ccccccc}
\hline $\begin{array}{c}\text { Sulfuric acid vapor } \\
\text { content } \\
\text { ppm }\end{array}$ & 2 & 5 & 7 & 10 & 13 & 15 \\
\hline 0 & 30.97 & 39.52 & 43.23 & 52.34 & 56.99 & 60.15 \\
5 & 73.35 & 74.09 & 74.83 & 79.29 & 81.52 & 81.53 \\
10 & 82.45 & 84.31 & 85.06 & 87.1 & 87.66 & 91 \\
15 & 91.19 & 92.68 & 96.398 & 99.19 & 101.04 & 101.23 \\
20 & 99.18 & 102.53 & 106.25 & 106.8 & 109.78 & 112.57 \\
\hline
\end{tabular}

\section{Result Analysis}

In order to effectively evaluate the calculation results, two statistical indicators, the mean square error and the coefficient of determination, are used to judge the fitting results. After calculation, the mean square error and coefficient of determination of the fitting results of the three formula forms are summarized in figure 1 and figure 2. 


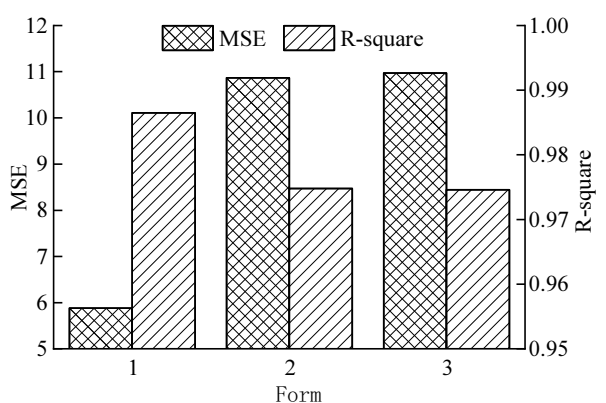

Figure 1. The distribution of the results of different formulas fitting Xiang Boxiang's experimental data

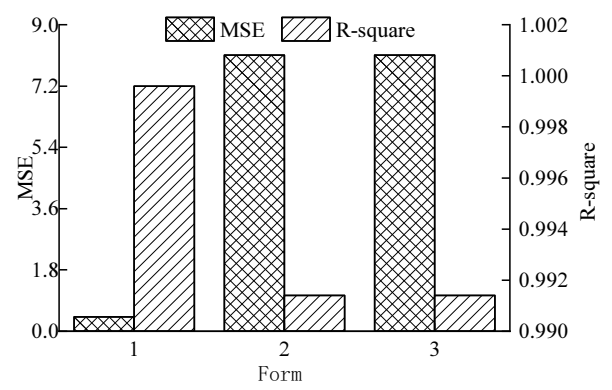

Figure 2. The distribution of the results of Taylor's experimental data fitted by different formulas

It can be seen from figures 1 and 2 that the mean square error of formula 1 is significantly lower than the other two calculation forms, the R-square value is always higher than 0.97 and the value is always higher than the other two calculation forms. It shows that the formula is similar to 1 and the calculation error of the fitting formula is the smallest and the regression is the best. Formula 1 is more sour and dew point test data fitting than the other two formulas. In other words, when the concentration of sulfur trioxide and water vapor in the flue gas is used as the basis for calculating the acid dew point, formula 1 should be selected for the fitting formula.

According to Taylor's formula 7, which is similar to 1, Xiang Boxiang's formula is 8. And according to the two formulas, the calculated three-dimensional diagram is shown in figures 3 and 4. The error distribution diagram is shown in figure 5 and figure 6.

$$
\begin{aligned}
& \frac{-570.5944}{t_{\text {adp }}+273.15}=-15.6207+0.4022 \log \left(r_{\mathrm{H}_{2} \mathrm{O}}+8.3662\right)+4.2912 \\
& \quad \cdot \log \left(r_{\mathrm{SO}_{3}}+52.9203\right)-0.0129 \log \left(r_{\mathrm{H}_{2} \mathrm{O}}+99.9829\right) \cdot \log \left(r_{\mathrm{SO}_{3}}+3.209\right) \\
& \frac{-719.53}{t_{\text {adp }}+273.15}=-3.6431+1.3961 \log \left(r_{\mathrm{H}_{2} \mathrm{O}}+56.5437\right)+0.6583 \\
& \cdot \log \left(r_{\mathrm{SO}_{3}}+4.2977\right)-0.0061 \log \left(r_{\mathrm{H}_{2} \mathrm{O}}-1.6016\right) \cdot \log \left(r_{\mathrm{SO}_{3}}+0.0061\right)
\end{aligned}
$$

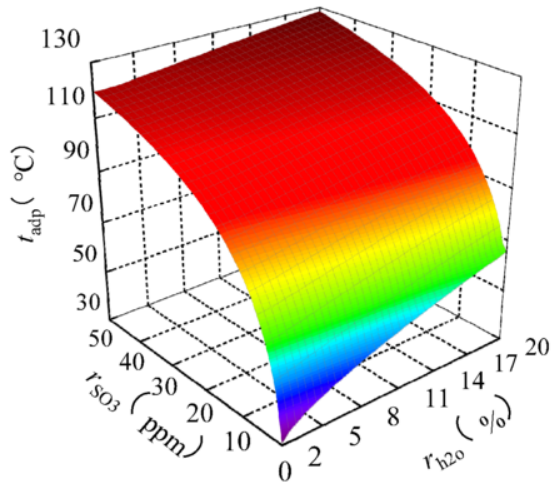

Figure 3. Three-dimensional graph of Xiang Baixiang's fitting result

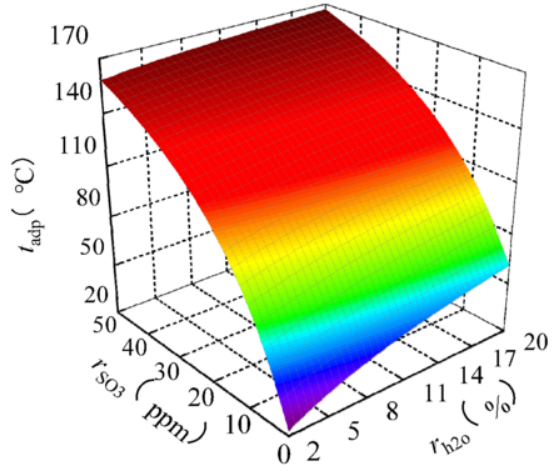

Figure 4. Three-dimensional diagram of Taylor fitting formula 
It can be seen from figures 5 and 6 that the absolute value of the calculation error of the fitting results obtained by using Xiang Boxiang's experimental data using calculation form 1 is within $7 \%$, and only the majority of the data does not exceed $5 \%$. The calculation errors of Taylor fitting results are all less than $3 \%$ in absolute value. Obviously, the fitting results of the above two experimental data meet the actual needs of the project.

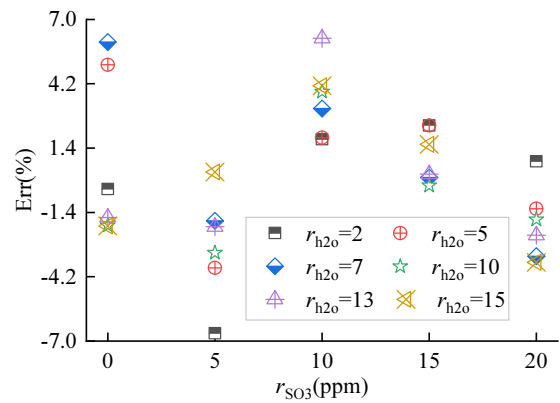

Figure 5. Xiang Boxiang Fitting Formula Error Distribution Diagram

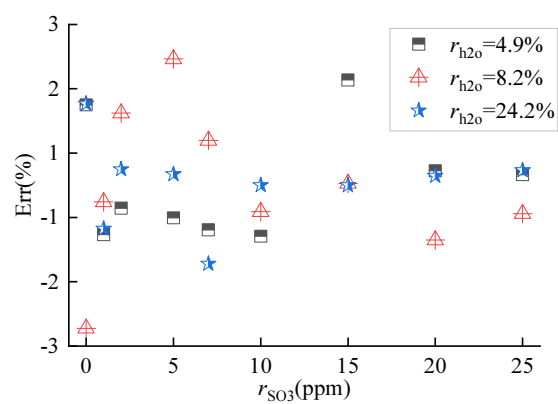

Figure 6. Taylor fitting formula error distribution diagram

\section{Comparison of Calculation Methods for Acid Dew Point}

In this paper, the flue gas with a flue gas vacuum of $800 \mathrm{~Pa}$ and a water vapor volume fraction of $9 \%$ is used as a benchmark to calculate the acid dew point value of the flue gas when the volume content of sulfur trioxide is different. When using the calculation formula of P.А.Лероеян to obtain the numerical distribution of the acid dew point calculation, it is assumed that about $1 \%$ of the sulfur dioxide in the flue gas will be further oxidized to sulfur trioxide. When the flue gas temperature is lower than $200{ }^{\circ} \mathrm{C}$, the sulfur trioxide is completely converted into Sulfuric acid vapor [15]. Through the summary analysis of the domestic coal type information mentioned in the "Practical Boiler Handbook", it can be seen that most of the coal type data mentioned in the handbook is basically $30-60 \mathrm{~g} / \mathrm{kJ}$, which is based on the assumptions. The converted ash content of coal is within this range, and the converted ash content is selected to be $45 \mathrm{~g} / \mathrm{kJ}$ for calculation. Figure 7 is obtained by calculating and summarizing the calculation formulas in Table 1 based on the above assumptions.

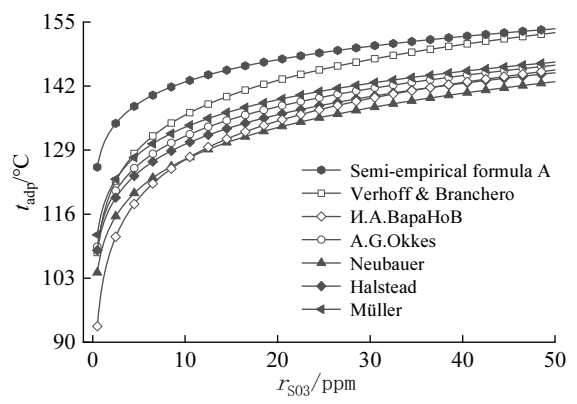

A)

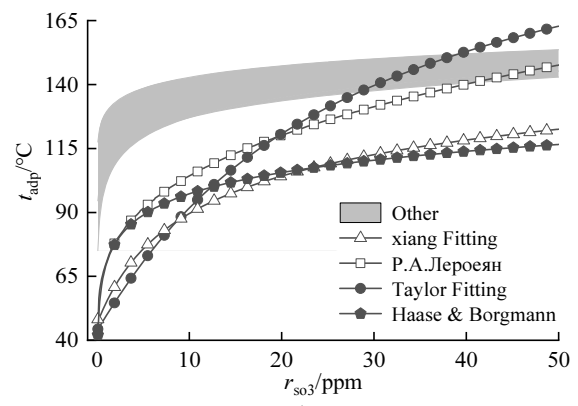

B)

Figure 7. Comparison of calculation values of different acid dew point calculation formulas 
It can be seen from figure $7 \mathrm{a}$ that the calculation value distribution of the common acid dew point calculation formula is relatively concentrated and the change trend is basically the same. Basically, the result of semi-empirical formula $\mathrm{A}$ is used as the upper limit, and the calculation formula of И.А.BapaHoB and Neubauer is the lower limit. When the concentration of sulfur trioxide is higher than $1 \mathrm{ppm}$, the calculated value is always higher than $95^{\circ} \mathrm{C}$, which is obviously inconsistent with the on-site measurement data carried out in related documents $[8,18]$, and is consistent with the current common acid dew point calculation formula pointed out by Song Jie [14] The theory that the calculated value is obviously high coincides with each other. This obviously leaves a higher margin for preventing the occurrence of low-temperature corrosion, but it obviously loses its guiding significance for units using low-temperature technology.

It can be seen from figure $7 \mathrm{~b}$ that the calculated values of P.A.Лероеян and Taylor have a wider numerical distribution range than other formulas. The calculated values of Haase\&Borgmann's formula and Xiang Boxiang's fitting formula are generally lower, but the trends of both The numerical distribution is roughly the same as that of P.A.Лероеян and Taylor.

The "Technical Regulations for Calculation of Combustion Meters in Thermal Power Plants" pointed out that Р.А.Лероеян has been verified in the operation of domestic coal-fired units. However, the calculation formula of P.A.Лероеян uses fuel receiving base composition, flue gas water vapor dew point and excess air coefficient as variables, while ignoring the influence of sulfur trioxide content in flue gas composition. When the unit is equipped with denitrification and low-temperature dust removal technologies, the sulfur trioxide content in the flue gas will change significantly, and the calculation accuracy of the calculation formula will have a large deviation at this time. However, because Taylor's calculation value is very close to the calculation value distribution of P.A.Лероеян calculation formula, Zhang Jianzhong [24] pointed out that this calculation method can be used as a reference form for the calculation of the acid dew point curve of coal-fired boiler flue gas.

When the concentration of sulfur trioxide is $1 \sim 5 \mathrm{~mL} / \mathrm{m} 3$, Haase\&Borgmann calculation formula and P.A.Лероеян calculation formula have a good agreement, and the relative error between the two is not more than $1.5 \%$ within this range. However, the calculated value of Haase\&Borgmann is significantly lower than other calculation methods when the concentration of sulfur trioxide is high. Tang Zhiyong[19] mentioned the foreign coal-fired flue gas acid dew point test statistics show that when the sulfur trioxide content in the flue gas is $50-60 \mathrm{~mL} / \mathrm{m} 3$, the flue gas acid dew point is roughly in the range of $120-175^{\circ} \mathrm{C}$. Obviously Haase\&Borgmann calculated The value is obviously low.

From the above analysis, it can be seen that when the content of sulfur trioxide in the flue gas is low, the calculated value of Haase\&Borgmann is relatively reasonable, and when the content of sulfur trioxide is high, the calculated value is obviously lower. It is inferred that the fitting formula of Haase\&Borgmann and Xiang Boxiang is more suitable The situation when the concentration of sulfur trioxide is low. In order to compare the applicability of the acid dew point calculation method, the common acid dew point calculation formula when the water vapor content in the flue gas is $9 \%$, the two experimental data fitting formulas and the summary of the experimental data collected by some foreign documents are drawn to obtain figure 8 . 


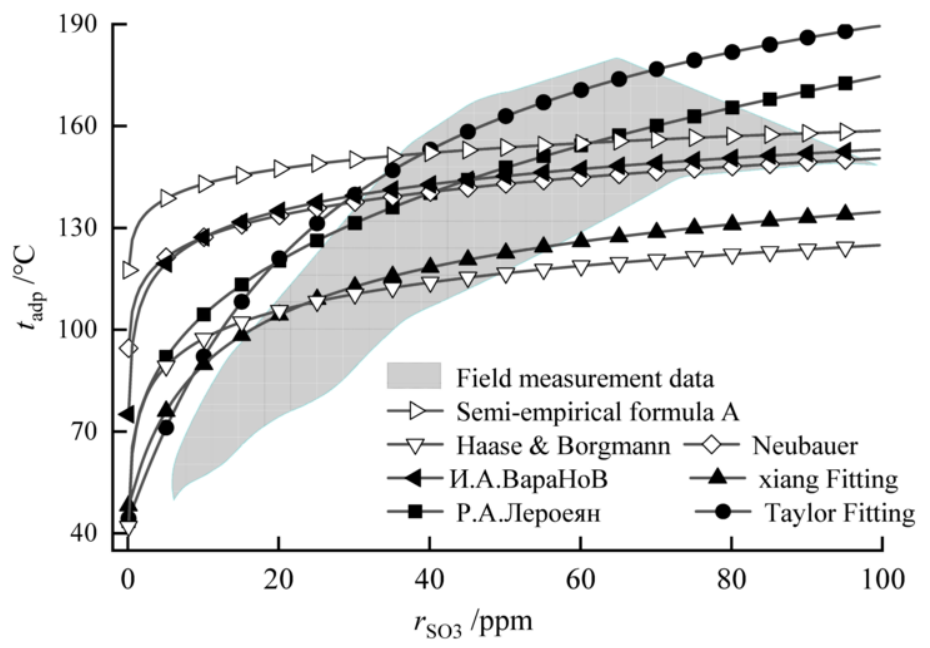

Figure 8. Comparison of different algorithm values and field measurement values

It can be seen from figure 8 that in terms of the data distribution, Taylor is basically close to the upper limit of the field test data. When the sulfur trioxide is lower than 20ppm, the calculated value of the Haase formula is closer to the measured data than other formulas, but the accuracy is lower. Taylor and Xiang Boxiang have a poor fit. When the concentration of sulfur trioxide is higher than 20ppm, Taylor's calculation value is obviously higher, but the data distribution is quite reasonable compared with the field measurement data.

\section{Conclusion}

Comparing the formula forms of common calculation formulas, it is found that the calculation form of Verhoff\&Branchero calculation formula is more suitable when using Taylor and Xiang Boxiang's data sheet to fit the calculation formula based on sulfur trioxide.

Comparing the obtained fitting formula and common calculation formulas, it is found that Taylor has better data distribution characteristics than the common acid dew point calculation formula and domestic and foreign field test data. However, when the sulfur trioxide concentration is lower than 20ppm At the time, the Haase calculation formula has higher calculation accuracy.

\section{References}

[1] Cheng Lin. Emission standard and treatment status of air pollutants in thermal power plants [J].Environmental protection frontier, 2014 (4) : 72-76.

[2] CHEN H, PAN P, JIAO J, et al. Low-temperature ash deposition and dewpoint corrosion of a coal-fired travelling grate boiler[J]. Applied Thermal Engineering, 2017, 117(Complete): 752-761.

[3] WANG D, BAO A, KUNC W, et al. Coal power plant flue gas waste heat and water recovery[J]. Applied Energy, 2012, 91(1): 341-348.

[4] Ma Youfu, Yang Lijuan, Lv Junfu. Technical and economic comparison of flue gas heat utilization system at the tail of power plant boiler [J].Journal of power engineering, 2017,37 (4) : 321-328. 
[5] WANG C, HE B, SUN S, et al. Application of a low pressure economizer for waste heat recovery from the exhaust flue gas in a 600MW power plant[J]. Energy, 2012, 48(1): 196-202.

[6] BOICHOT R, BERNIS A, GONZE E. Agglomeration of diesel particles by an electrostatic agglomerator under positive DC voltage: Experimental study[J]. Journal of Electrostatics, 2008, 66(5): 235-245.

[7] HAO W, PAN D, RUI Z, et al. Abatement of fine particle emissions from a Coal-Fired power plant based on the condensation of SO3 and water vapor[J]. Energy \& Fuels, 2017, 31(3): 3219-3226.

[8] Zhu Jianyue, Zhang Xiqi, Cao Jiangmin. Reform practice of flue gas heat recovery engineering based on acid dew point detection [J]. Boiler technology, 2017,48 (06) : 55-59.

[9] SONG J, YUAN H, DENG J. Experiment comparison between engineering acid DEW point and thermodynamic acid DEW point[C]//ICEMEE 2018. Kuala Lumpur, Malaysia : EDP Sciences, 2018: $1-5$.

[10] CHEN H, PAN P, SHAO H, et al. Corrosion and viscous ash deposition of a rotary air preheater in a Coal-Fired power plant[J]. Applied Thermal Engineering, 2016, 113: 373-385.

[11] ZHANG Yu-bo, YU Yan, LIU Jian-hua, et al. Adsorption characteristics of sulfuric acid mist on fly ash in Low-low temperature FLUE gas system[J]. Energy Procedia, 2017, 142: 3307-3312.

[12] Li Fei. Coal-fired boiler flue gas containing acid ash deposition characteristics and engineering acid dew point research [D].Jinan : Shandong University, 2014.

[13] ZARENEZHAD B, AMINIAN A. Accurate prediction of the dew points of acidic combustion gases by using an artificial neural network model[J]. Energy Conversion \& Management, 2011, 52(2): 911-916.

[14] ZARENEZHAD B, AMINIAN A. A multi-layer feed forward neural network model for accurate prediction of flue gas sulfuric acid dew points in process industries[J]. Applied Thermal Engineering, 2010, 30(6): 692-696.

[15] XIANG B, TANG B, WU Y, et al. Predicting acid dew point with a semi-empirical model[J]. Applied Thermal Engineering, 2016, 106: 992-1001.

[16] BAHADORI A. Estimation of combustion flue gas acid dew point during heat recovery and efficiency gain[J]. Applied Thermal Engineering, 2011, 31(8-9): 1457-1462.

[17] WANG Y C, TANG G H. Prediction of sulfuric acid dew point temperature on heat transfer fin surface[J]. Applied Thermal Engineering, 2016, 98: 492-501.

[18] WEI W, SUN F, SHI Y, et al. Theoretical prediction of acid dew point and safe operating temperature of heat exchangers for coal-fired power plants[J]. Applied Thermal Engineering, 2017, 123: 782-790.

[19] LI X, WU Z, ZHANG L, et al. An updated acid dew point temperature estimation method for air-firing and oxy-fuel combustion processes[J]. Fuel Processing Technology, 2016, 154: 204-209.

[20] SONG J, LI J, WANG S, et al. Experimental study of influence characteristics of flue gas fly ash on acid dew point[C]//IGRED 2017, UK : IOP Publishing, 2017: 1-7.

[21] Jia Mingsheng, Ling Changming. Influence factors and calculation method of flue gas acid dew point temperature [J].Industrial boiler, 2003 (6):31-35.

[22] Wang Chunbo, Qin Hongfei. The effect of oxy-fuel coal-fired boiler recirculation on flue gas acid dew point [J].Journal of Power Engineering, 2013,33 (10) : 765-769.

[23] Xie Tian, Li Yang, Zhou Yuanxiang, etc. A method for calculating acid dew point of boiler flue gas based on SO2 concentration in flue gas[J].Heat power generation, 2013,42 (12):118-121.

[24] Zhang Jianzhong. Discrimination and Discussion on Some Misunderstandings and Doubts in Calculation Method of Acid Dew Point of Flue Gas [J]. Boiler Technology, 2013, 44 (2):10-16.

[25] xiang baixiang.100MWe reheat biomass circulating fluidized bed boiler development [D].Beijing:Tsinghua University, 2014.

[26] Li Jun, Yan Weiping, Gao Baotong, et al. Calculation of flue gas acid dew point temperature of power station boilers [J]. Boiler technology, 2009, 40 (5):14 - 17.

[27] Xiang Baixiang, Xing Wenchong, Li Jianfeng, etc. Measurement and calculation of flue gas acid dew point correction of correlation [J]. Boiler technology, 2014,45 (01):1-4 + 71 . 